\section{Subclinical Calcified Nodules in Saphenous Vein Graft on High-Resolution Coronary Angioscopy}

Yohei Sumino, MD; Tomoyo Sugiyama, MD; Masahiro Hoshino, MD; Yoshihisa Kanaji, MD; Taishi Yonetsu, MD; Tsunekazu Kakuta, MD

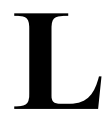
ong-term patency of saphenous vein graft (SVG) remains challenging. ${ }^{1}$ A 75 -year-old man on hemodialysis had undergone coronary artery bypass grafting (CABG) 11 years earlier. At the current presentation he underwent percutaneous coronary intervention (PCI) for SVG failure to the diagonal branch (Figure A). Intravascular ultrasound (IVUS) and optical coherence tomography (OCT) showed convex calcifications at the severe proximal anastomotic stenosis (Figure B,C) and tandem stenotic sites (Figure D,E). In addition, coronary angioscopy (CAS) indicated punctate red thrombus on a protruding mass (Figure F). These findings were suggestive of calcified nodules $(\mathrm{CN})$. A $3.5 \times 48-\mathrm{mm}$ stent was implanted (Figure G, yellow arrow) and he was discharged with an uneventful clinical course.

$\mathrm{CN}$ is defined pathologically as an accumulation of nodular calcification with disruption of fibrous cap. ${ }^{2}$ Given that this patient was asymptomatic, it was likely that red thrombus was the result of subclinical thrombosis. Development of CN could be one of the causes of SVG failure, particularly in hemodialysis patients. To the best of our knowledge, this is the first report on the evaluation of $\mathrm{CN}$ in SVG using IVUS, OCT and CAS.

Herein we present a case of subclinical CN in the SVG 11 years after $\mathrm{CABG}$, evaluated using multiple intracoronary imaging modalities.

\section{Disclosures}

The authors declare no conflicts of interest.

\section{References}

1. Dianati Maleki N, Ehteshami Afshar A, Parikh PB. Management of saphenous vein graft disease in patients with prior coronary artery bypass surgery. Curr Treat Options Cardiovasc Med 2019; 21: 12 .

2. Lee T, Mintz GS, Matsumura M, Zhang W, Cao Y, Usui E, et al. Prevalence, predictors, and clinical presentation of a calcified nodule as assessed by optical coherence tomography. JACC Cardiovasc Imaging 2017; 10: 883-891.

Received November 11, 2019; revised manuscript received January 6, 2020; accepted January 10, 2020; J-STAGE Advance Publication released online February 4, 2020 Time for primary review: 21 days

Department of Cardiology, Tsuchiura Kyodo General Hospital, Tsuchiura (Y.S., T.S., M.H., Y.K., T.K.); Department of Interventional Cardiology, Tokyo Medical and Dental University, Tokyo (T.Y.), Japan

Mailing address: Tsunekazu Kakuta, MD, Department of Cardiology, Tsuchiura Kyodo General Hospital, 4-1-1 Otsuno, Tsuchiura 300-0028, Japan. E-mail: kaz@joy.email.ne.jp

ISSN-1346-9843 All rights are reserved to the Japanese Circulation Society. For permissions, please e-mail: cj@j-circ.or.jp
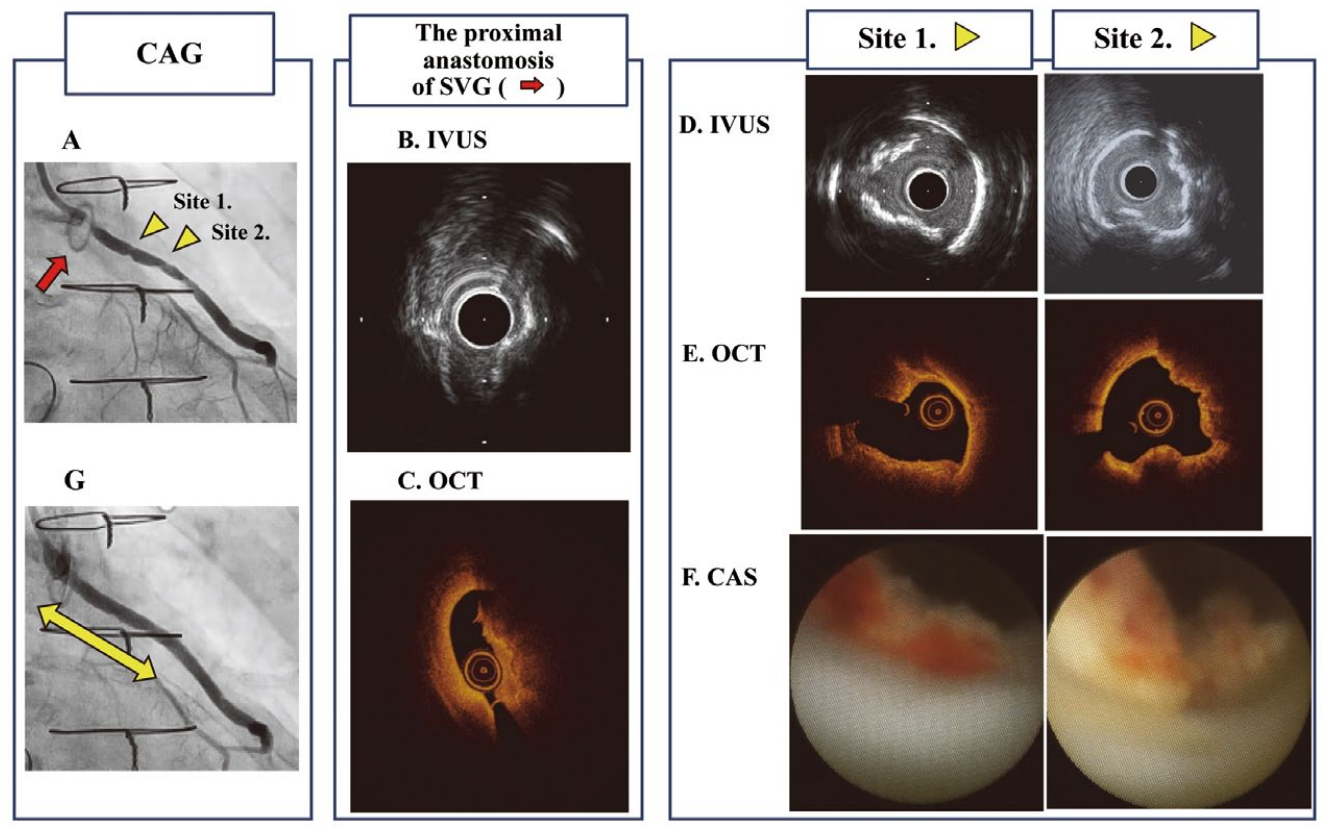

Figure. (A, G) Coronary angiography $(\mathrm{CAG})(\mathbf{A})$ before and $(\mathbf{G})$ after percutaneous coronary intervention. (B,C) Proximal anastomosis of the saphenous vein graft (SVG) on (B) intravascular ultrasound (IVUS) and (C) optical coherence tomography (OCT). (D-F) Intracoronary imaging: (D) IVUS, (E) OCT, (F) coronary angioscopy (CAS). 